\title{
Selective and Reliable Electrochemical Sensor Based on Polythionine/AuNPs Composites for Epinephrine Detection in Serum
}

\author{
Jianyong Huang ${ }^{1, *}$, Wentan Xu ${ }^{2,3}$, Yanqing Gong ${ }^{2}$, Shaohuang Weng ${ }^{2, *}$, Xinhua Lin $^{2}$ \\ ${ }^{1}$ Department of Pharmaceutical, Fujian Medical University Union Hospital, Fuzhou 350001, China. \\ ${ }^{2}$ Department of Pharmaceutical Analysis, Faculty of Pharmacy, Fujian Medical University, Fuzhou, \\ 350108, China \\ ${ }^{3}$ Jinjiang Municipal Hospital, Quanzhou 362200, China. \\ *E-mail: shweng@fjmu.edu.cn, jyhuangfjmu@ 126.com
}

doi: $10.20964 / 2016.10 .56$

Received: 19 July2016/ Accepted: 22 August 2016 / Published: 6 September 2016

This work used a highly selective electrochemical sensor based on polythionine/AuNPs composites (PTh/AuNPs) modified glassy carbon electrode (GCE) to detect epinephrine (EP). An elevated response of the oxidative behavior of EP was obtained on the PTh/AuNPs modified GCE in phosphate buffer saline ( $\mathrm{pH}$ 6.0), which allowed sensitive sensing of EP using the differential pulse voltammetry (DPV). The electrochemical sensor can selectively measure EP in a wide linear range from 1 to 40 $\mathrm{mg} / \mathrm{L}$ with a detection limit of $0.3 \mathrm{mg} / \mathrm{L}(\mathrm{S} / \mathrm{N}=3)$ and a high reproducibility in PBS. The developed electrochemical sensor can be favorably applied to detect EP in a diluted serum. Furthermore, the good linear regression between the EP concentrations and the currents in various diluted serum implied the potential of the proposed method as a promising candidate approach for complex clinical conditions.

Keywords:Epinephrine; Polythionine/AuNPs composites (PTh/AuNPs); Selective detection; Differential pulse voltammetry; Electrochemical sensor

\section{FULL TEXT}

(C) 2016 The Authors. Published by ESG (www.electrochemsci.org). This article is an open access article distributed under the terms and conditions of the Creative Commons Attribution license (http://creativecommons.org/licenses/by/4.0/). 